\title{
A UTILIZAÇÃO DO GEL DE PAPAÍNA NA REMOÇÃO DE LESÕES CARIOSAS DENTINÁRIAS
}

\section{THE USE OF PAPAIN GEL IN THE REMOTION OF INJURIES CARIOUS DENTIN}

\author{
Aline Aparecida Pereira* \\ Ilana de Carvalho Freitas* \\ Santuza Maria Souza de Mendonça"**
}

\section{RESUMO}

\begin{abstract}
O objetivo deste estudo é realizar uma revisão de literatura sobre a aplicabilidade do gel de papaína na remoção de lesões cariosas dentinárias. Utilizando-se os descritores cárie dentária, papaína, tratamento restaurador atraumático e processo químico foram identificados artigos indexados nas bases de dados Bireme, Lilacs, Pubmed/Medline, Scielo e Cochrane. Os artigos selecionados foram publicados entre 2001 e 2011 nos idiomas português, inglês ou espanhol. Também foram consultados livros sobre o assunto. O método mecânico é, tradicionalmente, utilizado para remoção de dentina cariada. Possui inconvenientes como necessidade de anestesia local e emprego de brocas para remoção de tecido cariado, o que pode gerar medo, dor ou desconforto para o paciente. Visando atenuar essas dificuldades, foram desenvolvidos métodos para remoção químico-mecânica da lesão cariosa dentinária em que um gel amolece a dentina infectada, preservando o tecido dentário sadio. Em 2003, foi criado no Brasil um produto totalmente nacional à base de papaína, cloramina e azul de toluidina. Ele age quimicamente na dentina infectada, promovendo a desestruturação do colágeno parcialmente degradado presente no tecido carioso necrosado. Estudos científicos revelaram que a utilização do gel de papaína, como método alternativo para remoção de dentina cariada, é atraumático, reduz a necessidade de anestesia, sendo indicado para tratamento de pacientes com necessidades especiais, crianças, adultos fóbicos e remoção de lesões cariosas muito próximas à polpa. Apresenta biocompatibilidade, atividade antimicrobiana, preserva tecido dentinário, diminuindo o risco de exposição pulpar.
\end{abstract}

DESCRITORES: Cárie Dentária • Papaína • Tratamento restaurador atraumático • Processo químico.

\section{ABSTRACT}

The objective of this study is to realise a review of literature on the application of papain in the remotion of dental caries. Using the descriptors dental caries, papain, dental atraumatic restorative treatment and chemical process indexed articles have been identified in the data base Bireme, Lilacs, Pubmed/Medline, Scielo and Cochrane. The selected articles were published between 2001 and 2011 in Portuguese, English and Spanish. Book on the issue were also consulted. The mechanical method is, traditionally, used to remove injured dentine. It has inconvenients such as the need of local anesthetics and the use of drills to remove the injured dentine tissue, which might generate fear, pain or uncomfort for the patients. Aiming to lower such difficulties, there has been developed methods for the removal of the dentine by chemical-mechanical method in which gel is used to soften the harmed dentine, preserving healthy dental tissue. In 2003 it was created in Brazil a totally national product based on papain, chloramines and blue toluidine. It acts chemically upon the harmed dentine, promoting the destructuration of the collagen partially degraded present in the necrosed tissue. Scientific studies have revealed that the use of the papain gel as alternative method for the remotion of infected dentine, non-traumatic, lessens the use of anesthetics, and it is indicated for treating patients with special needs, children, phobic adults and the removal of lesions very close to the pulp. It shows biocompatibility, antimicrobian activity, it preserves dental tissue, lessening the risk of pulp exposition.

DESCRIPTORS: Dental caries $\bullet$ Papain $\bullet$ Dental atraumatic restorative treatment $\bullet$ Chemical process.

\footnotetext{
* Acadêmica do Curso de Odontologia do Centro Universitário Newton Paiva/BH-MG, aline_pp@ymail.com

** Acadêmica do Curso de Odontologia do Centro Universitário Newton Paiva/BH-MG- ilanacfreitas@hotmail.com

*** Mestre em Odontologia, área de concentração Clínica Odontológica/UFMG; Professora Adjunta do Curso de Odontologia do Centro Universitário Newton Paiva/BH-MG
} 


\section{N T RO DUÇÃO}

A cárie dentária é uma doença multifatorial, infecciosa e crônica, causada por um desequilíbrio no processo de des-remineralização dentária. Esse desequilíbrio é induzido pela proliferação de bactérias cariogênicas, com consequente aumento na produção de ácido e diminuição do $\mathrm{pH}$ da saliva/placa para um nível crítico ${ }^{1}$.

Essa doença afeta o esmalte, a dentina e/ ou o cemento e, na ausência de tratamento, progride até que o dente seja completamente destruído. A destruição localizada dos tecidos duros é denominada lesão cariosa e pode ser observada clinicamente em diferentes níveis, que vão desde opacidades no esmalte (manchas brancas), difíceis de serem identificadas, até grandes cavidades que se estendem à polpa. Seu tratamento varia de acordo com a progressão da doença. Quando a lesão está restrita ao esmalte, as intervenções são conservadoras e envolvem desorganização da placa bacteriana, aplicação tópica de flúor e uso racional da sacarose, sendo contraindicado o tratamento restaurador. Selantes de cicatrículas e fissuras também podem ser utilizados no tratamento de lesões cariosas ativas não cavitadas. Como vantagem, propiciam a preservação da estrutura dentária, uma vez que o dente não precisa ser desgastado e nenhuma intervenção irreversível é envolvida. Quando a lesão está cavitada, utilizam-se brocas e/ ou tratamento químico-mecânico para remoção do tecido cariado, sendo necessário remover toda a dentina infectada para posterior restauração do dente $e^{2,3,4}$.

A apreensão ao procedimento odontológico ocorre por vários fatores, como dor e desconforto, medo da anestesia local e utilização de brocas para remoção de tecido cariado com consequente pressão e produção de calor sobre a polpa. O ruído excessivo provocado pelos motores de alta e baixa rotação também é motivo de incômodo para o paciente $\mathrm{e}^{5,6,7,8,9,10,11,12,13,14}$.

A busca constante por tratamentos e materiais, que facilitem a reabilitação odontológica, contribui para melhoria das condições bucais e sistêmicas dos pacientes. Têm sido propostos métodos mais conservadores para o tratamento de lesões cariosas cavitadas dentinárias, embasados na remoção da camada mais superficial da lesão (dentina infectada ou necrosada) e preservação da dentina afetada, passível de remineralização, com consequente preservação de estrutura dentária ${ }^{1,6,8}$, $15,16,17$.

Atualmente, a Odontologia restauradora tem se preocupado mais com a preservação da estrutura dentária e utilizado técnicas minimamente invasivas no tratamento das lesões de cárie. Para a remoção de dentina cariada têm sido propostos métodos alternativos ao emprego de instrumentos rotatórios convencionais que são instrumentação ultrassônica, laser de alta potência, microabrasão a ar e soluções químicas. Todos esses métodos têm como objetivo reduzir a necessidade de anestesia local, diminuir a sintomatologia dolorosa e eliminar o desconforto sonoro

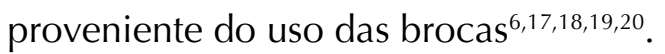

As soluções químicas empregadas na remoção de dentina cariada foram desenvolvidas com base no processo de amolecimento do tecido cariado com sua posterior remoção através de instrumentos manuais, preservando estruturas dentárias, não causando irritação pulpar ou desconforto para o paciente $\mathrm{e}^{13,18,20,21,22,23,24,25}$.

A dentina infectada possui uma consistência amolecida/umedecida e alta concentração de bactérias, não podendo ser reparada devido à desnaturação irreversível das fibras de colágeno. A dentina afetada é semelhante à dentina sadia, possuindo dentina peritubular densa e mineralizada, poucas bactérias, e é passível de remineralização ${ }^{1,7,24,26,27,28}$.

A remoção químico-mecânica é a alternativa mais acessível para remoção de dentina cariada quando comparada ao método convencional, sendo que a grande dificuldade durante a remoção da dentina está em determinar quando parar a escavação. Essa técnica consiste na utilização de soluções que interagem diretamente com o pré-colágeno degradado da lesão, favorecendo a remoção do tecido cariado através da utilização de ferramentas manuais. Está indicada para remoção de dentina cariada presente em lesões cariosas cavitadas e sem comprometimento pulpar. Na maioria das vezes, o procedi-
PEREIRA AA

FREITAS IC

MENDONÇA SMS

A UTILIZAÇÃO DO

gel DE PAPAÍNA

NA REMOÇÃo DE

LESÕES CARIOSAS

DENTINÁRIAS

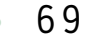

UNIV, CID, SÃO
PAULO
$2013 ; 25(1): 68-$
76, JAN-ABR 
PEREIRA AA

FREITAS IC

MENDONÇA SMS

A UTILIZAÇÃO DO GEL DE PAPAÍNA

NA REMOÇÃO DE

LESÕES CARIOSAS

DENTINÁRIAS

70

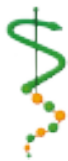

REV, ODONTOL.

UNIV. CID . SÃO

PAULO

$2013 ; 25(1): 68-$

76 , JAN-ABR:
I SSN 1983-5183

mento é realizado sem o uso de anestesia e sem queixa de dor, promovendo ao paciente experiência odontológica positiva com mínima intervenção e máxima preservação de estrutura dentária sadia, removendo-se apenas o tecido com comprometimento irreversível ${ }^{1,6,7,8,12,14,16,23,24,29}$.

Diante disso, o presente estudo objetivou conhecer, através de uma revisão de literatura, a composição do gel de papaína; seu mecanismo de ação; suas indicações; técnica de aplicação; benefícios; limitações; associações com o Tratamento Restaurador Atraumático e possíveis interferências na força de adesão de materiais restauradores.

\section{METODOLOG IA}

Procedeu-se à busca de artigos científicos nas bases de dados bibliográficos Bireme, Lilacs, Pubmed/Medline, Scielo e Cochrane. Os descritores utilizados para a busca dos artigos foram Cárie Dentária, Papaína,Tratamento Restaurador Atraumático e Processo Químico. Todos foram extraídos da listagem de Descritores em Ciências da Saúde da Biblioteca Virtual de Saúde, disponível em http://decs. bvs.br. Seus correspondentes em inglês e espanhol também foram empregados, respeitando-se o(s) idioma(s) utilizado(s) nas bases de artigos selecionadas. Como critérios de inclusão dos artigos estão: 1) Artigos de revisão de literatura, pesquisa científica ou casos clínicos que discutiam sobre a utilização de métodos químico-mecânicos, especialmente aqueles à base do gel de papaína, na remoção de dentina cariada; 2) Artigos localizados nas bases bibliográficas Bireme, Lilacs, Pubmed/ Medline, Scielo e Cochrane com auxílio dos descritores citados; 3) Artigos publicados nos idiomas português, inglês ou espanhol; 4) Artigos publicados nos últimos 10 anos, ou seja, entre 2001-2011; 5) Artigos disponíveis on-line ou pelo Programa de Comutação Bibliográfica (COMUT). Como critérios de exclusão estão: 1) Artigos que não tinham como tema principal a utilização de métodos químico-mecânicos, especialmente o gel à base da papaína, na remoção de dentina cariada; 2) Artigos indexados em outras bases bibliográficas diferentes da Bireme, Lilacs, Pub-
med/Medline, Scielo e Cochrane; 3) Artigos localizados por outros descritores; 4) Artigos publicados em outros idiomas diferentes do português, inglês ou espanhol; 5) Artigos publicados fora do período entre 2001-2011; 6) Artigos não disponibilizados on-line ou através do Programa de Computação Bibliográfica (COMUT).

\section{REVISÃO DE LITERATURA E DISCUSSÃO}

\section{Histórico}

A remoção químico-mecânica do tecido cariado foi primeiramente descrita, quando o hipoclorito de sódio a 5\% foi utilizado para promover a dissolução da dentina cariada. Essa substância revelou-se instável e agressiva aos tecidos sadios. Em 1975, o hipoclorito de sódio 5\% foi incorporado a uma mistura de hidróxido de sódio, cloreto de sódio e glicina, denominada GK 101. O GK 101 propunha remoção da dentina cariada com preservação de estrutura dentária sadia, porém apresentava dificuldades na execução da técnica de aplicação e ação proteolítica muito lenta 1,6,8,10,11,14,18,21 22,24,27,30,31,32,

Em 1986, foi incorporada ao produto GK 101 uma solução contendo ácido aminobutírico, glicina, cloreto de sódio e hidróxido de sódio. Caridex ${ }^{\mathrm{TM}}$, como foi denominado esse sistema, apresentava alguns inconvenientes, como a necessidade de um reservatório para seu transporte, grande volume de solução, além de precisar de aquecimento, dificultando sua aplicação 1,6,7,8,9,10,11,12,14,15,18,21,22,24,27,30,31,32. .

Com a finalidade de superar esses problemas, foi criado, em 1990, o Carisolv ${ }^{\mathrm{TM}}$ juntamente com curetas especiais sem corte que trabalham num ângulo de $90^{\circ}$, possibilitando menor risco de remoção de tecido dentinário sadio. Esse produto é composto por três aminoácidos (ácido glutâmico, leucina e lisina) e hipoclorito de sódio. Os três aminoácidos presentes no Carisolv ${ }^{\mathrm{TM}}$, que possuem diferentes cargas, regulam melhor a força solubilizadora do hipoclorito de sódio, promovendo a remoção de dentina infectada e manutenção de dentina afetada. Como as fibras colágenas contaminadas possuem uma ligação mais fraca, serão as primeiras a serem dissolvidas, assim, o amolecimento do tecido cariado é favorecido, 
bem como sua delicada remoção. Apesar de proporcionar vantagens como dispensar o uso de anestesia, técnica de aplicação simples e confortável para o paciente, o Carisolv ${ }^{\mathrm{TM}}$ apresentava alto custo, além de frequentemente precisar utilizar instrumentos rotatórios para acesso à cavidade. $1,6,7,8,10,11,12,14,15,18,24,27,31,32$.

Com o intuito de melhorar a utilização dos sistemas de remoção químico-mecânica, em 2003 foi criado no Brasil, pela Prof ${ }^{a}$ Dr $^{a}$ Sandra Kalil Bussadori, um produto denominado de Papacárie ${ }^{\circledR}$. Ele consiste num gel à base de papaína, cloramina, e azul de toluidina $1,7,8,10,11,12,14,15,18$ ,21,22,24,27,31,32,33.

\section{Composição do gel}

A papaína é uma endoproteína presente no látex das folhas e frutos de mamão verde ou maduro, Carica papaya. É semelhante à pepsina humana que tem atividade antibacteriana, bacteriostática e anti-inflamatória, acelerando o processo cicatricial. 6,8,11,15,18,22,27,30,32,34,35,36

A cloramina é um composto formado por cloro e amônia. Possui propriedades bactericidas e desinfetantes e é largamente utilizada como solução irrigante de canais radiculares. É utilizada também para amolecer quimicamente a dentina cariada, sendo que a porção degradada do colágeno da dentina cariada é clorada pela solução utilizada na remoção química e mecânica da cárie. Essa substância afeta a estrutura secundária e/ou quaternária do colágeno, rompendo as pontes de hidrogênio e facilitando a remoção do tecido cariado $11,14,15,21,22,31,32,33$

O azul de toluidina é um corante que se liga à parede bacteriana e age como um potente agente antimicrobiano quando combinado com o uso da tecnologia do laser de baixa potência. ${ }^{32,33}$.

\section{Mecanismo de ação}

A papaína age apenas no tecido lesado visto que não possui a antiprotease plasmática, alfa1-anti-tripsina, responsável pela inibição da digestão de proteínas em tecidos normais. Nos tecidos lesados, a papaína age "quebrando" as moléculas de colágeno parcialmente degradadas pela ação da cárie, já que tem a capacidade de digerir células mortas. Após aplicação do gel na dentina cariada, há uma forma- ção de bolhas de oxigênio na superfície dentinária com posterior turvação do gel, indicando a quebra das moléculas de colágeno e sinalizando que se pode iniciar a remoção do tecido cariado. $\mathrm{O}$ aspecto vítreo do tecido dentinário no fundo da cavidade evidencia a completa remoção do tecido infectado $1,6,7,10,11,14,15,21,26,27,30,31,3$ $3,34,35,36$.

\section{Indicações}

O gel de papaína é indicado para remoção de dentina cariada em pacientes com necessidades especiais, crianças, adultos fóbicos e, muitas vezes, dispensa o uso de anestesia local. Também tem aplicação na remoção de dentina cariada em lesões cariosas muito profundas e próximas à polpa, amolecendo o tecido cariado, não necessitando de instrumentos rotatórios. Pode e deve ser utilizado em saúde pública, uma vez que tem baixo custo. O gel de papaína é atóxico, não oferecendo risco aos tecidos bucais em caso de contato. Esse produto reúne características importantes como praticidade, facilidade de utilização, baixo custo, além de dispensar o uso de anestesia local 12,18,22,32.

\section{Técnica de aplicação do gel}

Após a realização do isolamento relativo, o fabricante recomenda aplicar o produto sobre a dentina cariada, dentro da cavidade, durante 30 segundos. Após esse período, o gel, que apresenta coloração verde-translúcida, torna-se turvo. Depois da mudança de coloração do gel, a dentina amolecida cariada e infectada deve ser raspada com instrumento manual sem corte (parte inativa da cureta). Pereira et al. ${ }^{30}(2004)$ indicam a aplicação de gel de papaína por 30 segundos nas lesões cariosas agudas e de 40 a 60 segundos em lesões cariosas crônicas.

Caso o tecido cariado não tenha sido totalmente removido, deve-se reaplicar o produto até que a cavidade apresente aspecto vítreo. Após essa fase, deve-se lavar e secar a cavidade e dar seguimento à técnica restauradora $6,7,9,11,12,15,30,33$.

Influência do uso do gel de papaína na polimerização do sistema adesivo

Tem sido demonstrado que as superfícies dentinárias formadas após a remoção química de tecido cariado são muito irregulares, com saliências e retenções. A
PEREIRA AA

FREITAS IC

MENDONÇA SMS

A UTILIZAÇÃO DO

GEL DE PAPAÍNA

NA REMOÇÃo DE

LESÕES CARIOSAS

DENTINÁRIAS

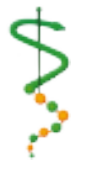

REV, ODONTOL.

UNIV. CID, SÃo

PAULO

2013; 25(1): $68-$

76, JAN-ABR 
PEREIRA AA

FREITAS IC

MENDONÇA SMS

A UTILIZAÇÃO DO GEL DE PAPAÍNA

NA REMOÇÃO DE

LESÕES CARIOSAS

DENTINÁRIAS

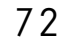

REV, ODONTOL.

UNIV, CID, SÃO

PAULO

$2013 ; 25(1): 68-$

76 , JAN-ABR presença de resíduos químicos do gel de papaína pode comprometer a polimerização do sistema adesivo, interferindo na interface dente/restauração, aumentando o risco de infiltração marginal e, consequentemente, de lesão cariosa secundária adjacente a restaurações de resina composta ${ }^{23,35,37}$.

O uso de adesivo autocondicionante, que não utiliza o condicionamento ácido, exerce maior interferência na polimerização do sistema adesivo. Nesses casos, é mais provável encontrar vestígios de smear layer contaminada com resíduos do gel de papaína na interface dente-restauração. Apesar disso, não foram observadas diferenças na qualidade de restaurações feitas após a remoção de dentina cariada com o método químico-mecânico ou com método convencional. No entanto, é necessário realizar um acompanhamento longitudinal dessas restaurações, uma vez que o produto é novo ${ }^{23,38}$.

\section{Benefícios e limitações da utiliza- ção do gel de papaína}

O gel de papaína é um método de remoção químico-mecânico de dentina cariada que proporciona conforto e bem estar ao paciente durante sua aplicação. Esse gel apresenta biocompatibilidade, atividade antimicrobiana, preserva tecido dentinário, diminuindo o risco de exposição pulpar. Sua aplicação é favorecida por sua consistência de gel e coloração, que vai de esverdeada a turva, o que possibilita melhor visualização do procedimento que pode ser feito sob isolamento relativo ${ }^{1,14,32,33,39}$.

Apesar de todos os benefícios apresentados, esse método não exclui o uso de instrumentos rotatórios para remoção de esmalte sem suporte com objetivo de ampliar a abertura da cavidade de maneira a facilitar o acesso do gel e curetas. Nos casos de indicação de coroas indiretas, o gel não consegue dar forma ao preparo cavitário, sendo também necessária a utilização de motores e instrumentos rotató$\operatorname{rios} 7,10,11,26,27,30$.

\section{TRA \\ Associação entre gel de papaína e}

O tratamento restaurador atraumático (TRA) consiste na remoção manual do tecido cariado com auxílio de instrumen- tos manuais com posterior restauração do dente com cimento ionômero de vidro. Apresenta técnica relativamente fácil, material/equipamento simples e custo reduzido $^{40,41}$.

O gel de papaína pode ser utilizado como alternativa na remoção de dentina cariada durante o TRA. A aplicação do gel facilita a remoção do tecido cariado, uma vez que contribui para o amolecimento da dentina infectada e sua posterior remoção. Dessa forma, a adequação do meio bucal pode ser realizada com maior rapidez, segurança e conforto para o paciente, possibilitando a preservação da estrutura dentária e evitando tratamentos restauradores mais complexos $5,40,42,43$.

\section{CONSIDERAÇÕES FINAIS}

O gel de papaína foi criado visando diminuir os inconvenientes da remoção mecânica da lesão cariosa. Age amolecendo a dentina infectada e preservando tecido dentário sadio. Tem ação bactericida, bacteriostática e anti-inflamatória. É recomendado para o tratamento de pacientes que procuram uma alternativa ao método convencional. Seu uso é facilitado pela sua consistência de gel que favorece a permanência do produto no local desejado. Sua alteração de cor, que varia do verde translúcido ao verde turvo, possibilita a identificação do momento adequado para a remoção da dentina cariada. Alia praticidade, efetividade e segurança, sendo atraumático. Pode ser utilizado sobre isolamento relativo, uma vez que não é tóxico aos tecidos bucais. É um excelente aliado no tratamento de crianças, pacientes especiais e adultos fóbicos e apresenta como limitação a necessidade do uso de instrumentos rotatórios para acesso à lesão cariosa ou preparo cavitário. Possui baixo custo, o que viabiliza sua utilização na rede pública. Estudos revelaram que a utilização do gel de papaína com a posterior aplicação do adesivo autocondicionante, exerce uma maior interferência na polimerização do sistema adesivo. O gel de papaína pode ser associado ao tratamento restaurador atraumático, possibilitando uma maior preservação de estrutura dentinária, segurança e conforto para o paciente. 
1. Motta LJ, Martins MD, Porta KP, Bussadori SK. Aesthetic restoration of deciduous anterior teeth after removal of carious tissue with Papacarie. Indian J Dent Res 2009 Jan-abr;20(1):117-20.

2. Thylstry A, Fejerskov O. Cariologia clínica. 3 ed. São Paulo Santos; 2001.

3. Fejerskov O, Kidd E. Cárie dentária: a doença e seu tratamento clínico. São Paulo: 7 Letras; 2005.

4. Mendonça S, Moreira N, Magalhães C. Dentina cariada: uma revisão dos métodos e critérios clínicos empregados em sua remoção. JBD, 2002 abr.jun.;1(2):166-74.

5. Avila S, Machado PEM, Fontes LBC, Cavalcanti AL, Maciel SML, Granville-Garcia AF. Associação da técnica do ART e o papacárie no tratamento odontológico de crianças com medo. Int J Dent [serial on the Internet]. 2008 [Acesso em: 2011 01 março]; 7(2): Disponível em: http://www.ufpe.br/ijd/index.php/exemplo/article/ viewFile/94/84.

6. Granville-Garcia AF, Menezes VA, Rocha MRS, Cavalcanti AL. Remoção químico-mecânica de tecido cariado: bases biológicas e materiais utilizados. Stomatos [serial on the Internet]. 2009 [Acesso em: 201101 março]; 15(28): Disponível em: www.ulbra.br/odontologia/stomatos/v15n28jan-jun2009/67.remocao-quimico-mecanica.pdf.

7. Honorio H, Rios D, Bresciani E, Sakai V, Machado M. Aspectos clínicos da utilização do gel de papaína e cloramina na remoção da cárie dentária. RFO [serial on the Internet]. 2009 [Acesso em: 201128 março]; 14(1): Disponível em: www.upf.br/ download/editora/revistas/rfo/14-01/61_65.pdf.

8. Motta LJ, Bussadori SK, Guedes CC, Reda SH, Santos EM. Avaliação in vitro do potencial antimicrobiano de dois sistemas para remoção químico-mecânica de dentina cariada: Carisolv e Papacárie. Arquivos em Odontologia 2005 out.-dez.;41(4):296-305.

9. Faustino-Silva DD, Leitune VCB, Collares FM, Figueiredo MC, Samuel SMW. Resistência de união do adesivo à dentina de dentes decíduos submetidos a dois métodos de remoção químico-mecânica da cárie. RFO [serial on the Internet]. 2009 [Acesso em: 201103 março]; 14(3): Disponível em: http://files.bvs.br/upload/S/1413-4012/2009/ v14n3/a234-238.pdf.

10. Teitelbaum AP, Martins GC, Castilho AL, Giovani EM, Czlusniak GD, Wambier DS. Remoção química-mecânica da cárie dentária com o gel Papacárie- relato de caso clínico. Rev Inst Ciênc Saúde [serial on the Internet]. 2009 [Acesso em: 2011 28 fev.]; 27(1): Disponível em: http://files.bvs.br/upload/S/0104-1894/2009/v27n1/ a016.pdf.

11. Bussadori SK, Castro LC, Galvao AC. Papain gel: a new chemo-mechanical caries removal agent. J Clin Pediatr Dent 2005 Winter;30(2):115-9.

12. Carrillo CM, Tanaka MH, Cesar MF, Camargo MA, Juliano Y, Novo NF. Use of papain gel in disabled patients. J Dent Child (Chic) 2008 Sep-Dec;75(3):222-8.

13. Correa FN, Rocha Rde O, Rodrigues Filho LE, Muench A, Rodrigues CR. Chemical versus conventional caries removal techniques in primary teeth: a microhardness study. J Clin Pediatr Dent 2007 Spring;31(3):187-92.

MENDONÇA SMS

A UTILIZAÇÃO DO

GEL DE PAPAÍNA

NA REMOÇÃO DE

LESÕES CARIOSAS

DENTINÁRIAS

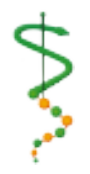

REV. ODONTOL.

UNIV. CID. SÃO

PAULO

$2013 ; 25(1): 68$

76 , JAN-ABR 
PEREIRA AA

FREITAS IC MENDONÇA SMS

A UTILIZAÇÃO DO GEL DE PAPAÍNA

NA REMOÇÃO DE LESÕES CARIOSAS DENTINÁRIAS

REV, ODONTOL : UNIV. CID. SÃO PAULO: 2013; 25(1): 68$76, J A N-A B R$
14. Martins MD, Fernandes KP, Motta LJ, Santos EM, Pavesi VC, Bussadori SK. Biocompatibility analysis of chemomechanical caries removal material Papacarie on cultured fibroblasts and subcutaneous tissue. J Dent Child (Chic) 2009 May-Aug;76(2):123-9.

15. Silva LR, Motta LJ, Reda SH, Façanha RAZ, Bussadori SK. Papacárie- um novo sistema para remoção química e mecânica do tecido cariado- relato de caso clínico. Rev Paul Odontol 2004 nov.-dez.;26(6):4-8.

16. Bertassoni LE, Marshall GW. Papain-gel degrades intact nonmineralized type I collagen fibrils. Scanning 2009 Nov-Dec;31(6):253-8.

17. Ziskind D, Kupietzky A, Beyth N. First-choice treatment alternatives for caries removal using the chemomechanical method. Quintessence Int 2005 Jan;36(1):9-14.

18. Dália RCS, Gomes MP, Menezes Filho PF, Guimarães RP, Mariz ALA, Silva CHV. Dentística ultraconservadora- métodos alternativos de preparos cavitários. RFO [serial on the Internet]. 2009 [Acesso em: 20011 abr.]; 14(2): Disponível em: http:// files.bvs.br/upload/S/1413-4012/2009/v14n2/a168-173.pdf.

19. Corts JP, Cedrés C. Prevención y restauración en cariología. Actas Odontol 2008 jul.-dic;5(2):22-35.

20. Redá SH, Motta LJ, Guedes CC, Figueiredo MC, Bussadori SK. El uso de un gel a base de papaína en odontopediatría: un caso clínico. Bol Asoc Argent Odontol Niños 2005 sept;34(3):19-22.

21. Araújo NC, Oliveira APB, Rodrigues VMS, Andrade PMMS. Análise da microinfiltração marginal em restaurações de cimentos ionoméricos após a utilização do papacárie. Rev Odont Ciênc [serial on the Internet]. 2008 [Acesso em: 201128 março]; 23(2): Disponível em: http://revistaseletronicas.pucrs.br/fo/ojs/index.php/fo/article/ view/2354/3050n.

22. Araújo NC, Oliveira APB, Rodrigues VMS, Andrade PMMS. Avaliação do selamento marginal de restaurações adesivas após o uso do gel de papaia. Pesqui Bras Odontopediatria Clin Integr [serial on the Internet]. 2007 [Acesso em: 01 abril. 2011]; 7(1).

23. Mello HR, Costa KT, Gonzalez M, Fraga RC. Influência do uso do papacárie nas propriedades de sistemas adesivos. Rev Bras Odontol [serial on the Internet]. 2008 [Acesso em: 201108 março]; 65(1): Disponível em: http://revista.aborj.org.br/index. php/rbo/article/viewFile/4/4.

24. Bittencourt ST, Pereira JR, Rosa AW, Oliveira KS, Ghizoni JS, Oliveira MT. Mineral content removal after Papacarie application in primary teeth: a quantitative analysis. J Clin Pediatr Dent 2010 Spring;34(3):229-31.

25. Maragakis GM, Hahn P, Hellwig E. Chemomechanical caries removal: a comprehensive review of the literature. Int Dent J 2001 Aug;51(4):291-9.

26. Bussadori SK, Guedes CC, Fernandes KPS, Martins MD, Masuda MS. Utilização do gel à base de papaína para a remoção química mecânica do tecido cariado. Rev Assoc Paul Cir Dent 2006 60(6):450-3.

27. Bussadori SK, Guedes CC, Hermida Bruno ML, Ram D. Chemo-mechanical removal of caries in an adolescent patient using a papain gel: case report. J Clin Pediatr Dent 2008 Spring;32(3):177-80. 
28. Bussadori SK, Guedes CC, Martins MD, Fernandes KPS, Santos EM. Gel a base de papaína: una nueva alternativa para la remoción química y mecánica de la caries. Acta Odontol 2006 Jul.-Dec.;3(2):35-9.

29. Correa FN, Rocha RO, Soares FZ, Rodrigues-Filho LE, Rodrigues CR. Fluorescence of primary dentine after chemomechanical and conventional rotary excavation. Eur Arch Paediatr Dent 2008 Sep;9(3):126-9.

30. Pereira AS, Silva LR, Motta LJ, Bussadori SK. Remoção químico mecânica de cárie por meio do gel papacárie. RGO 2004 nov/dez;52(5):358-8.

31. Lopes MC, Mascarini RC, da Silva BM, Florio FM, Basting RT. Effect of a papainbased gel for chemomechanical caries removal on dentin shear bond strength. J Dent Child (Chic) 2007 May-Aug;74(2):93-7.

32. Mejia MP, Moncada DS, Alva EP, Peña SZ, Zeballos WG, Tataje JO, et al. Influencia del uso de papacárie en el sellado marginal de obturaciones directas. Odontol Sanmarquina [serial on the Internet]. 2008 [Acesso em: 201109 março]; 11(2): Disponível em: http://sisbib.unmsm.edu.pe/bvrevistas/odontologia/2008_n2/pdf/a03v11n2. pdf.

33. Silva LR, Murillo JH, Santos EM, Guedes-Pinto AC, Bussadori SK. Utilización del gel de la papaya para la remoción de la caries-reporte de um caso com seguimiento clínico de um año. Acta Odontol Venez 2005 Mai.;43(2):1-10.

34. Jawa D, Singh S, Somani R, Jaidka S, Sirkar K, Jaidka R. Comparative evaluation of the efficacy of chemomechanical caries removal agent (Papacarie) and conventional method of caries removal: an in vitro study. J Indian Soc Pedod Prev Dent 2010 AprJun;28(2):73-7.

35. Piva E, Ogliari FA, Moraes RR, Cora F, Henn S, Correr-Sobrinho L. Papain-based gel for biochemical caries removal: influence on microtensile bond strength to dentin. Braz Oral Res 2008 Oct-Dec;22(4):364-70.

36. Bortoletto CC, Ferrari JCL, Motisuki C, Spolidorio DMP, Santos-Pinto L. Atividade antimicrobiana de um novo biomaterial utilizado na remoção químico-mecânica da cárie. Rev Odontol UNESP [serial on the Internet]. 2005 [Acesso em: 201120 março]; 34(4): Disponível em: http://rou.hostcentral.com.br/PDF/v34n4a10.pdf.

37. Botelho Amaral FL, Martao Florio F, Bovi Ambrosano GM, Basting RT. Morphology and microtensile bond strength of adhesive systems to in situ-formed caries-affected dentin after the use of a papain-based chemomechanical gel method. Am J Dent 2011 Feb;24(1):13-9.

38. Gianini RJ, do Amaral FL, Florio FM, Basting RT. Microtensile bond strength of etchand-rinse and self-etch adhesive systems to demineralized dentin after the use of a papain-based chemomechanical method. Am J Dent 2010 Feb;23(1):23-8.

39. Kotb RM, Abdella AA, El Kateb MA, Ahmed AM. Clinical evaluation of Papacarie in primary teeth. J Clin Pediatr Dent 2009 Winter;34(2):117-23.

40. Oliveira MT, Bittencourt ST, Oliveira MDS, Hübe R, Pereira JR. Avaliação clínica do desempenho de TRA (tratamento restaurador atraumático) associado a um agente químico de remoção de cárie. Rev Odonto Ciênc [serial on the Internet]. 2009 [Acesso em: 201111 março]; 24(2): Disponível em: http://revistaseletronicas.pucrs. br/fo/ojs/index.php/fo/article/view/2790/4002. 
PEREIRA AA

FREITAS IC MENDONÇA SMS

A UTILIZAÇÃO DO GEL DE PAPAÍNA NA REMOÇÃO DE LESÕES CARIOSAS DENTINÁRIAS

41. de Menezes Abreu DM, Leal SC, Frencken JE. Self-report of pain in children treated according to the atraumatic restorative treatment and the conventional restorative treatment--a pilot study. J Clin Pediatr Dent 2009 Winter;34(2):151-5.

42. Bussadori SK, Guedes CC, Bachiega JC, Santis TO, Motta LJ. Clinical and radiographic study of chemical-mechanical removal of caries using Papacarie: 24-month follow up. J Clin Pediatr Dent 2011 Spring;35(3):251-4.

43. Bussadori SK, Martins MD, Fernandes KPS, Guedes CC, Motta LJ, Redá SH, et al. Avaliação da biocompatibilidade in vitro de um novo material para a remoção química e mecânica da cárie- Papacárie. Pesqui Bras Odontopediatria Clin Integr [serial on the Internet]. 2005 [Acesso em: 201124 fevereiro]; 5(3): Disponível em: http://redalyc.uaemex.mx/pdf/637/63750309.pdf.

Recebido em: 24/11/2011

Aceito em: 09/04/2012 